\title{
Happy birthday, Helmut Münstedt
}

\author{
Florian J. Stadler • Joachim Kaschta
}

Received: 25 July 2011 / Accepted: 11 August 2011 / Published online: 8 September 2011

(C) Springer-Verlag 2011

In this special issue of Rheologica Acta, friends and coworkers of Prof. Helmut Münstedt, who is one of the leading experts in the field of polymer rheology, celebrate his 70th birthday. Münstedt had a long and successful career. After studying physics at the universities of Braunschweig and then in Stuttgart for his Ph.D. with Wolfgang Pechhold, he joined the polymer laboratory of BASF in 1972. There, he focused on polymer rheology and especially on elongational rheology, which at this time was an almost unknown area. Colleagues from this time praise his certain professorial touch. In 1982, he left rheology for the study of intrinsically electrically conductive polymers. The research of his team resulted in the first prototype of a polymer battery. However, BASF closed down this research effort, as electrically conducting polymers at that time were insufficiently stable. Following this, he transferred to technical sales and was promoted to director, responsible for selling over 450,000 tons of LDPE per year

This paper is dedicated to Professor Helmut Münstedt, Friedrich-Alexander Universität Erlangen-Nürnberg on the occasion of his 70th birthday.

\section{F. J. Stadler $(\varangle)$}

School of Semiconductor and Chemical Engineering, Chonbuk National University, Baekjero 567, Deokjin-gu, Jeonju, Jeonbuk, 561-756, Republic of Korea

e-mail: fjstadler@jbnu.ac.kr

\section{J. Kaschta}

Institute of Polymer Materials, Department of Materials Science, University Erlangen-Nürnberg, Martensstr. 7, 91058 Erlangen, Germany at that time. This could have become a career in the upper management of BASF. However, the scientific world had not forgotten Münstedt and pushed him to become professor. After having turned down a faculty position at the Technical University Berlin in 1989, he eventually joined Friedrich-Alexander University Erlangen-Nürnberg (FAU) in 1993, where he took the Lehrstuhl für Polymerwerkstoffe (Institute of Polymer Materials, LSP) to succeed Friedrich R. Schwarzl. In Erlangen, he returned to his beloved rheology and also built a world-class analytics lab. The institute allowed him and his $\mathrm{PhD}$ students to cooperate with macromolecular chemists to obtain polymers with welldefined topographies so that he could explore their rheology. Among the cooperation partners were the groups of Eisenbach (Stuttgart), Lunkwitz (Dresden), and Kaminsky (Hamburg). Münstedt used rheology to probe molecular architecture. LSP became one of the few places in the world, where a complete analytical and rheological characterization of polymers can be performed in house.

It is very characteristic for Münstedt's patient perseverance that he invested a significant portion of his startup funding into Laser-Doppler Velocimetry, which he had researched briefly in the early 1980s. With his experience of experimenting with hot polymer melts, this became one of the most successful research tools at LSP; it led to the discovery of mechanisms of several melt fracture phenomena such as shark skin and pressure oscillations. Recent interest in these topics by many other research groups, the collaborations with many modeling specialists, and the organization of session on this topic at rheological meetings are proof to Prof. Münstedt's vision in investing in this-at that time, odd-topic. 
Besides his rheology and fluid dynamics oriented research, Münstedt excelled in several other research areas. In 1995, he collaborated with Prof. Guggenbichler of the childrens' hospital of FAU to develop antimicrobial catheters and founded a company to produce these catheters. However, time was not ripe for this, and the company went bankrupt.

He followed up with a project to apply antimicrobial properties to other daily life products such as toothbrushes. Only 5 years later, the first silver toothbrush appeared on the market. Nowadays, many countries, especially in East Asia (namely Korea and Japan), have nano-silver products in many areas such as lunchboxes, personal care, and clothing. Other important research topics in his group at FAU were metal-polymer composites especially for three-dimensional molded interconnecting electronic devices. Among the intended applications are magnetic extruded films, polymer electretes, and transparent nanocomposites. Furthermore, an important aspect of his research focused on polymerbased implants, which are either biodegradable or biological stable (Fig. 1).

\section{Working style}

When anybody from the rheological community hears the name Münstedt, two associations come to mind. Firstly, they see him as one of the two fathers of elongational rheometry (the other one was Joachim Meissner, both having worked at BASF for many years). The second thing mentioned frequently is his thrive for performing experiments with utmost precision and reliability. In his long career, he always managed to keep up the highest quality standards for experimental data, which might have lowered the scientific output (in terms of number of papers) somewhat, but it made him as one of the worldwide reference laboratories in terms

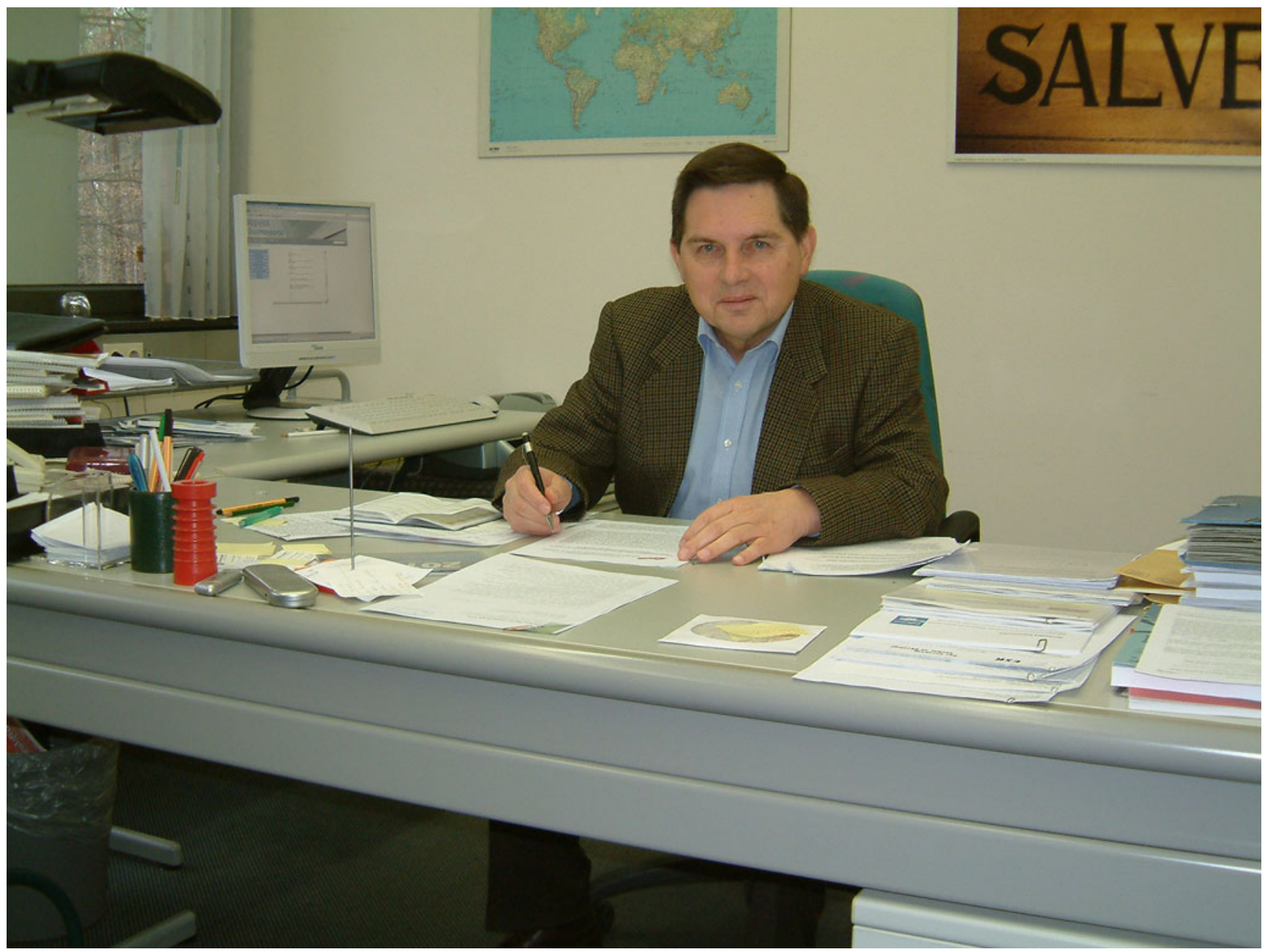

Fig. 1 Prof. Dr. Helmut Münstedt at his desk 
of quality of rheological data. The authors remember an occasion where his sense of precision came fully into play: on a meeting discussing the cooperation between the Leibniz-Institute of Polymer Research Dresden, Martin-Luther University Halle-Wittenberg, and LSP, concerning the results of the influence of electron beam and $\gamma$-irradiation on polypropylene, which yielded a rather large difference, Münstedt was reluctant to accept these results as correct, as only one series of five materials was irradiated by $\gamma$-rays. So he wanted to restart the-in the meantime-dismantled Co-source to obtain another series of materials, whose preparation and characterization would take another 6-9 months. In his eyes, the "angemessene, wissenschaftliche Sorgfalt" (adequate, scientific care) demanded this.

Besides his demand for precise scientific work, Helmut Münstedt loved discussions with his Ph.D. students and scientific coworkers. In these discussions, he was open to new ideas, but it required good arguments to convince him of the validity of a new approach or idea. Foreign students will remember the hospitality of Helmut Münstedt and his wife Gabi. Presumably, this attitude dates back to his time as "Leverhume Fellow" at the City University of London. Frequently, they invited the students for a hike on the weekend in the hilly area of the Fränkische Schweiz (Franconian Switzerland) or for lunch or dinner to their home.

\section{The Münstedt tensile rheometer}

Helmut Münstedt is probably best known for the "Münstedt" tensile rheometer (MTR), which essentially is a tensile testing machine, capable of stretching at polymer sample with an exponentially increasing speed, which is suspended in an oil bath to compensate for gravity.

During his long career, he never stopped to improve its performance. Figure 2 shows the latest MTR model. What sets the MTR apart from other elongational rheometers is the possibility to get up to, access to the whole sample during all stages of the test, and the possibility to not only perform stressing tests but also be able to do creep and creep recovery tests.

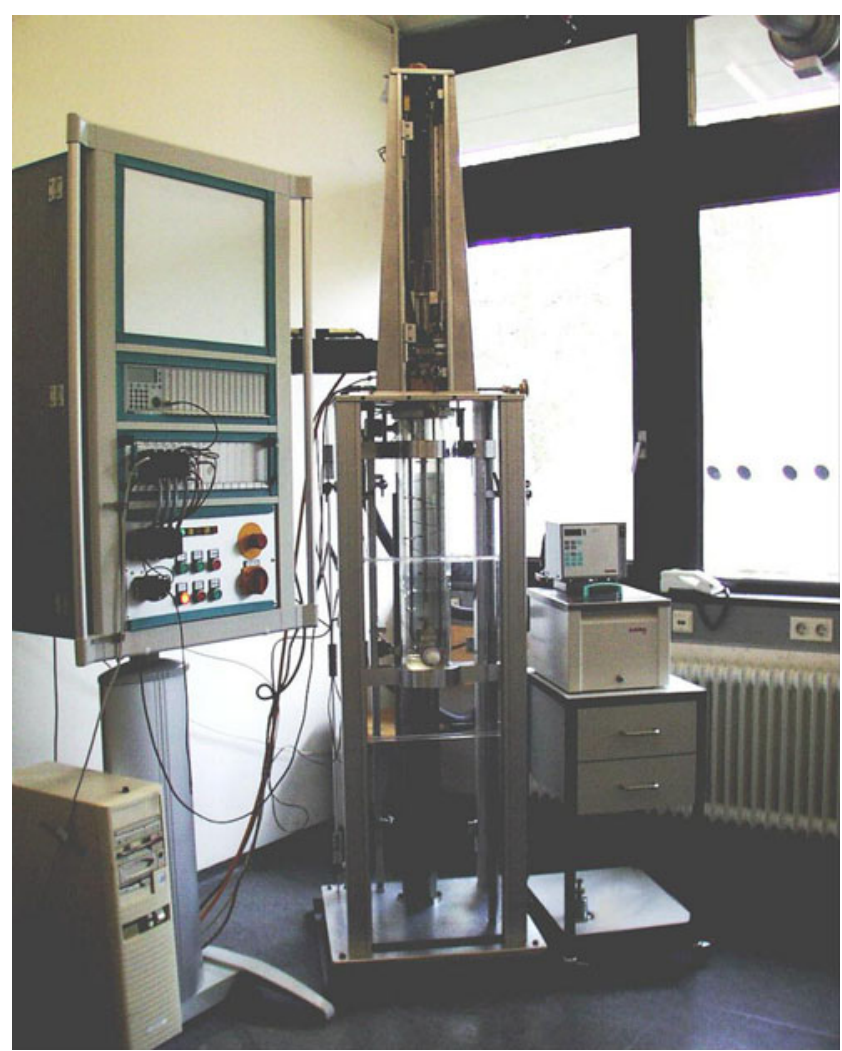

Fig. 2 The Münstedt tensile rheometer

\section{Outlook}

Throughout his academic career, Helmut Münstedt always tried to transfer the research knowledge into industrial use. Numerous collaborations with industrial partners in Europe and the US testify to his reputation.

In his career so far, he published over 170 articles in peer-reviewed journals (of which more than 35 appeared in Rheologica Acta), numerous patents, and many more articles in conference proceedings. Although he is officially retired now, he is still active and advises currently three $\mathrm{PhD}$ students himself. We hope that he and his wife, who has accompanied him to numerous rheological conferences and is, therefore, known to many of us personally, will stay healthy and active in science for many years to come. 